\title{
Pituicytoma Associated with Serum Adrenocorticotropic Hormone Elevation
}

\author{
Issei Fukui, Yasuhiko Hayashi, Iku Nambu, Mitsutoshi Nakada \\ Department of Neurosurgery, Graduate School of Medical Science, Kanazawa University, Kanazawa, Japan \\ Email: ifukui@med.kanazawa-u.ac.jp
}

How to cite this paper: Fukui, I., Hayashi, Y., Nambu, I. and Nakada, M. (2016) Pituicytoma Associated with Serum Adrenocorticotropic Hormone Elevation. Open Journai of Modern Neurosurgery, 6, 105-110. http://dx.doi.org/10.4236/ojmn.2016.64018

Received: September 16, 2016

Accepted: October 15, 2016

Published: October 18, 2016

Copyright $\odot 2016$ by authors and Scientific Research Publishing Inc. This work is licensed under the Creative Commons Attribution-NonCommercial International License (CC BY-NC 4.0). http://creativecommons.org/licenses/by-nc/4.0/

\begin{abstract}
Background: Pituicytoma is a rare benign tumor of the neurohypophysis or hypophyseal stalk. Endocrinological abnormalities derived from this tumor are even rarer. Although three cases of pituicytoma with elevated plasma adrenocorticotropic hormone $(\mathrm{ACTH})$ have been reported previously, the etiological mechanisms remain unknown. Case Description: We present a 47-year-old woman who was referred to a hospital complaining of headache. On investigation using magnetic resonance imaging (MRI), a tumor was detected in the sellar region. Elevation of basal ACTH and serum cortisol was identified, suggesting an ACTH-producing pituitary adenoma. However, physical findings and results of other hormonal examination showed no evidence of Cushing disease. The tumor had been detected incidentally eight years earlier when MRI was performed, and showed considerable enlargement on this consultation. Endoscopic endonasal transsphenoidal surgery was performed in order to remove the tumor completely. The histopathological diagnosis was pituicytoma. The patient's postoperative clinical course was excellent, and both ACTH and cortisol levels returned to normal following surgery. Conclusions: It appears that ACTH was being secreted from the tumor cells. We discuss the possible mechanism of ACTH elevation in cases of pituicytoma.
\end{abstract}

\section{Keywords}

Pituicytoma, Adrenocorticotropic Hormone, Transsphenoidal Surgery

\section{Introduction}

Pituicytomas are tumors originating from the glial cells of the neurohypophysis or hypophyseal stalk. This rare condition is estimated to constitute $0.1 \%$ of all primary brain tumors [1]. Clinical presentations are similar to non-functioning pituitary adenomas, and no characteristic neuroradiological findings have been observed [2]. Thus, it is of- 
ten difficult to diagnose pituicytoma accurately before histological confirmation. Although the tumor is benign in nature (WHO grade 1), the recurrence rate is relatively high even after subtotal tumor resection [3]. The 5-year overall and progress in-free survival rates are reported as $91.7 \%$ and $100 \%$ respectively [1]. Endocrinological deficiencies associated with pituicytomas appear to unusual [4]. Indeed, three cases of elevated plasma adrenocorticotropic hormone (ACTH) level have been reported previously [3]-[5]. Here, we present a rare case of a pituicytoma with elevated plasma ACTH level without features of Cushing disease, and discuss the potential mechanism of ACTH elevation.

\section{Case History}

A 47-year-old woman presented at a local hospital complaining of headache. A tumor located in the sellar region was detected via magnetic resonance imaging (MRI). The tumor did not appear to be in contact with the optic nerves and the patient's headache disappeared immediately; therefore, conservative observation was carried out. Eight years later, the patient presented at the hospital again due to headache. It was discovered that the tumor had grown significantly since the previous consultation and the patient was transferred to our hospital for further examination and treatment. On admission, elevation of basal ACTH and cortisol was detected: ACTH, $66.0 \mathrm{pg} / \mathrm{ml}$ (normal < $46 \mathrm{pg} / \mathrm{ml}$ ) and cortisol $21.4 \mu \mathrm{g} / \mathrm{dl}$ (normal 6.2 - $19.4 \mu \mathrm{g} / \mathrm{dl}$ ). Morning and evening cortisol levels were $24.8 \mathrm{mg} / \mathrm{dL}$ and $3.7 \mathrm{mg} / \mathrm{dL}$ respectively, which were considered as above the normal range. An overnight suppression test with a low dose of dexamethasone (0.5 $\mathrm{mg}$ ) showed sufficient suppression of cortisol level from $24.8 \mathrm{nmol} / \mathrm{L}$ to $0.7 \mathrm{nmol} / \mathrm{L}$. Physical examination revealed the patient's height as $160 \mathrm{~cm}$, body weight as $54.6 \mathrm{~kg}$, and body mass index as 21.3. She presented no physical abnormalities characteristic of Cushing disease. MRI revealed a $15 \times 12 \times 18 \mathrm{~mm}$ sellar mass extending into the suprasellar region and making contact with the optic chiasm. The mass was recognized as isointense on both T1 and T2-weighted images (WI). Dynamic scanning after bolus injection of gadolinium demonstrated strong, homogenous enhancement on T1-WI during the early phase, suggesting remarkable hypervascularity of the tumor. However, there is no evidence of intratumoral hemorrhage was seen. Invasion of neither the cavernous sinus nor the sphenoid sinus was found (Figure 1). Although ACTH-producing pituitary adenoma with hyper vascularity was suspected preoperatively, the results of hormonal examinations were not consistent with a diagnosis of Cushing disease. Endoscopic endonasal transsphenoidal surgery was performed to remove the tumor with extracapsular dissection. No massive intraoperative hemorrhage was encountered, with a total blood loss of $300 \mathrm{ml}$.

Histopathological examination using hematoxylin and eosin staining showed that the tumor cells were oval-spindle in shape with eosinophilic cytoplasm, and variable in size. No evidence of mitosis and necrosis was seen. Immunohistochemistry indicated diffuse expression of S-100 and vimentin, and focal expression of glial fibrillary acidic protein in the cytoplasm. On the other hand, Periodic acid-Schiff and epithelial membrane an- 
tigen staining were negative (Figure 2). The diagnosis of pituicytoma was based on these histopathological findings. Additional immunohistochemistry showed positive staining for ACTH in the cytoplasm and NeuroD1, a transcription factor expressed in all ACTH-secreting adenomas, in the nucleus (Figure 3).

The patient's postoperative clinical course was excellent except for the occurrence of transient diabetes insipidus. During two years of follow up after surgery, MRI revealed no recurrence of the tumor, and both ACTH and cortisol levels stayed within the normal range.

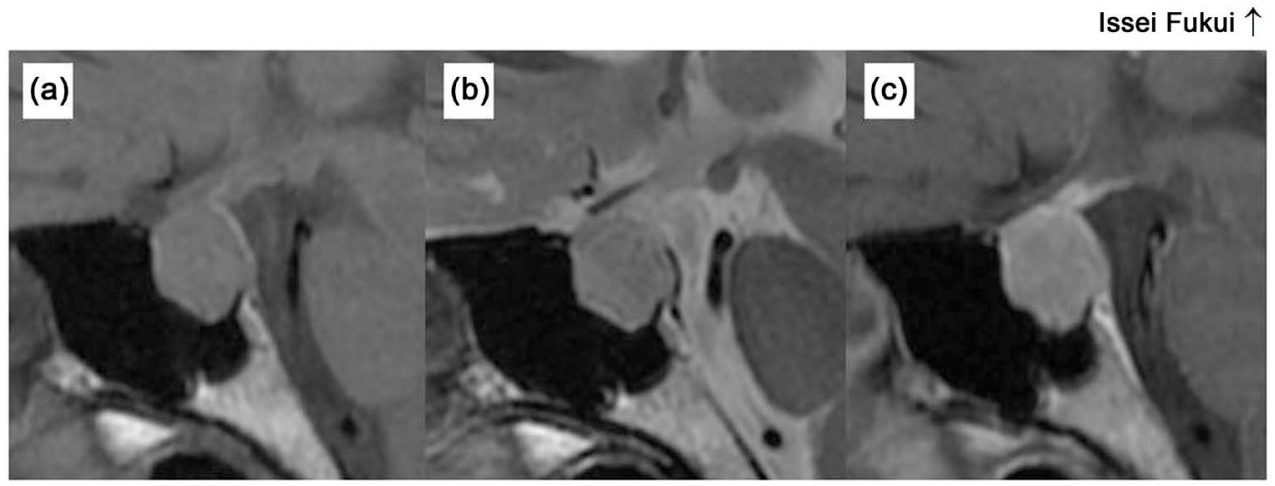

Figure 1. Tumor located in the sellar and supra sellar regions. Sagittal view MRI scans show isointensity without contrast medium on both T1-WI and T2-WI ((a) and (b), respectively). The tumor presented with marked homogenous enhancement after contrast medium administration (c).

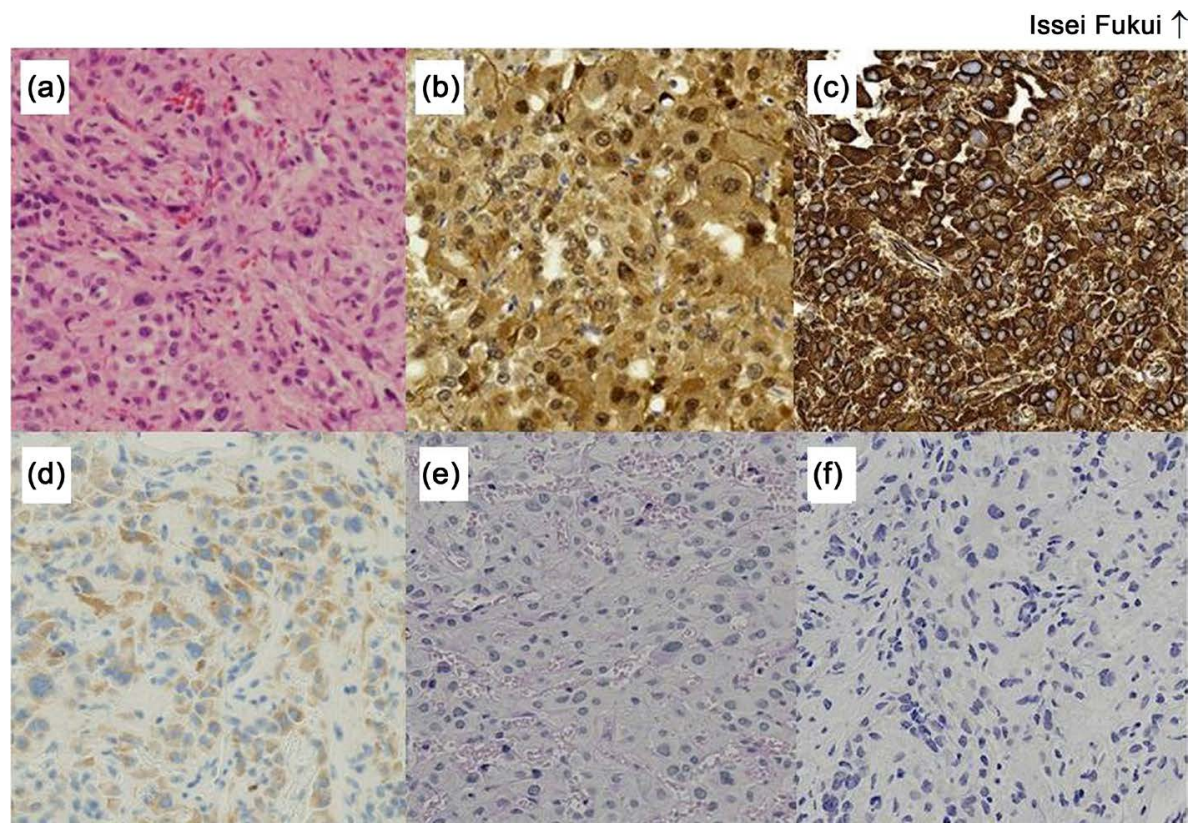

Figure 2. Histopathological findings: hematoxylin and eosin staining (a) The micrograph shows tumor cells in sizes oval-spindle shaped with eosinophilic cytoplasm. There is no evidence of mitosis and necrosis. Immunohistochemistry micrograph showing diffuse expression of S-100 (b) and vimentin (c), and focal expression of glial fibrillary acidic protein (d). Periodic acid-Schiff (e) and epithelial membrane antigen staining $(f)$ were negative. (Each magnification: $\times 200$ ). 


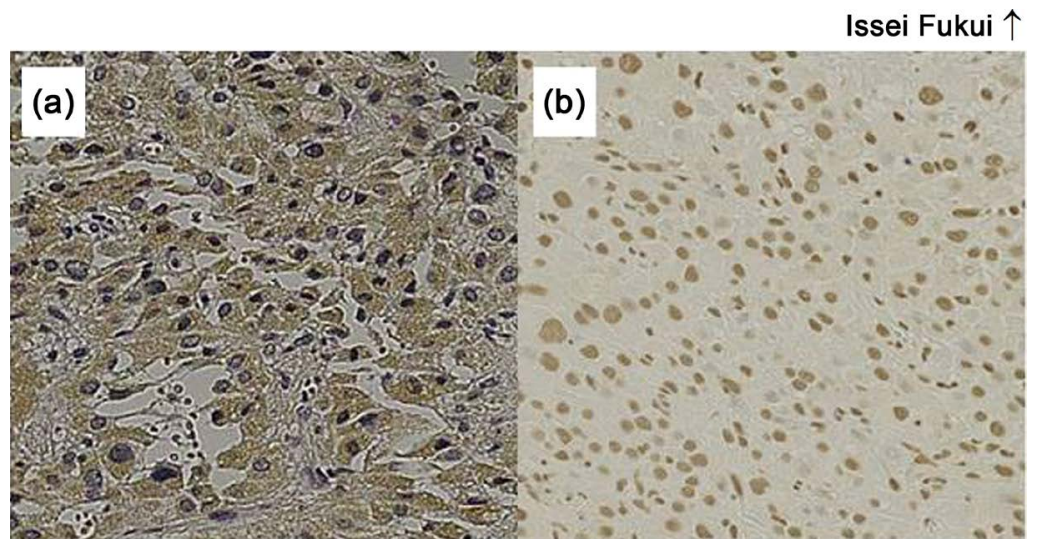

Figure 3. Positive staining for ACTH in the cytoplasm (a) and NeuroD1 in the nucleus (b). (Each magnification: $\times 200)$.

\section{Discussion}

The endocrinopathies most frequently associated with pituicytoma are hyperprolacti-nemia (25.4\%), hypogonadism relating to testosterone (9.8\%), and diabetes insipidus (3.9\%) [4]. Although the tumor originates from the neurohypophysis, diabetes insipidus is an unusual clinical manifestation of pituicytoma at the preoperative stage. The pituicyte, which is the principal cell of the pituicytoma, is considered a special type of astrocyte, and acts as an osmotic sensor regulating neurohypophyseal hormone output [6]. It was speculated that pituicytoma begins growth in the posterior or lower portion of the pituitary stalk and that loss of function may be compensated for by the upper neurohypophysis [7].

Three cases of pituicytoma with elevated ACTH level have been reported previously [4]. One of these was diagnosed endocrinologically as Cushing disease [3]. In our case, elevated levels of both ACTH and cortisol were recognized, but no clinical symptoms characteristic of Cushing disease were found. In addition, a low-dose dexamethasone loading test resulted in suppression of cortisol and normal circadian cortisol rhythm. These results were not compatible with typical hormonal characteristics of Cushing disease. In the previous case described above, where pituicytoma demonstrated an endocrinological response compatible with Cushing disease, histopathological examination revealed pituicytoma with Crooke's cells [3]. Crooke's cells are nonneoplasticcorticotrophs, with cytoplasmic accumulation of cytokeratin filaments, which are observed in aggressive variants of corticotroph adenomas [8]. In the case of our patient, Crooke's cells were not detected, although immunohistochemistry showed positive staining for ACTH and NeuroD1.

Based on these results, we consider two possible mechanisms for elevated ACTH in case of pituicytoma. Firstly, pituicytomas are generally thought to consist largely of pituicytes and have no endocrine function. However, Canacci et al. suggested that pituicytomas may have some endocrine function relating to ACTH [9]. They report using electron microscopy to identify a pituicytoma with fibrous bodies and secretory gra- 
nules similar to those seen in pituitary adenoma. It is possible that pituicytoma arises from the stromal folliculo-stellate cells of the adenohypophysis, which are able to differentiate into endocrine cells. If this is the case, pituicytomas could possess some endocrine function, leading to elevated levels of ACTH. Secondly, Vrontakis et al. demonstrated that corticotroph extension or migration into the posterior lobe of the pituitary, known as basophil invasion [10]. This phenomenon is found in approximately $62 \%$ of autopsy series [11]. It was reported that basophil invasion can occur as early as fetal life [12]. Although the hormonal activity of basophil invasion is not known, pituicytoma may originate from the invasion of the posterior lobe by corticotrophs, which undergo neoplastic transformation and therefore show positive staining for ACTH and NeuroD1.

In conclusion, we have presented a case of pituicytoma associated with elevated serum ACTH elevation without symptoms of Cushing disease. The mechanisms of ACTH elevation are not yet clearly understood. Pituicytomas like this one are similar to pituitary adenomas in clinical presentation, and can be difficult to diagnose accurately without histopathological examination.

\section{References}

[1] Shibui, S. (2014) The Committee of Brain Tumor Registry of Japan: Report of Brain Tumor Registry of Japan (2001-2004). Neurologia Medico-Chirurgica (Tokyo), 54, 9-32. http://dx.doi.org/10.2176/nmc.sup.2014-0001

[2] Shah, B., Lipper, M.H., Laws, E.R., Lopes, M.B. and Jr. Spellman, M.J. (2005) Posterior Pituitary Astrocytoma: A Rare Tumor of the Neurohypophysis: A Case Report. American Journal of Neuroradiology, 26, 1858-1861.

[3] Schmalisch, K., Schittenhelm, J., Ebner, F.H., Beuschlein, F., Honegger, J. and Beschorner, R. (1990) Pituicytoma in a Patient with Cushing's Disease: Case Report and Review of the Literature. Pituitary, 15, 10-16. http://dx.doi.org/10.1007/s11102-010-0262-3

[4] Chakraborti, S., Mahadevan, A., Govindan, A., Sridhar, K., Mohan, N.V., Satish, I.R., et al. (2013) Pituicytoma: Report of Three Cases with Review of Literature. Pathology-Research and Practice, 209, 52-58. http://dx.doi.org/10.1016/j.prp.2012.10.006

[5] Uesaka, T., Miyazono, M., Nishio, S. and Iwaki, T. (2002) Astrocytoma of the Pituitary Gland (Pituicytoma): Case Report. Neuroradiology, 44, 123-125. http://dx.doi.org/10.1007/s002340100654

[6] Rosso, L. and Mienville, J.M. (2009) Pituicyte Modulation of Neurohormone Output. Glia, 57, 235-243. http://dx.doi.org/10.1002/glia.20760

[7] Nakasu, Y., Nakasu, S., Saito, A., Horiguchi, S. and Kameya, T. (2006) Pituicytoma. Two Case Reports. Neurologia Medico-Chirurgica (Tokyo), 46, 152-156.

http://dx.doi.org/10.2176/nmc.46.152

[8] George, D.H., Scheithauer, B.W., Kovacs, K., Horvath, E., Jr. Young, W.F., Lloyd, R.V., et al. (2003) Crooke'S Cell Adenoma of the Pituitary: An Aggressive Variant of Corticotroph Adenoma. The American Journal of Surgical Pathology, 27, 1330-1336. http://dx.doi.org/10.1097/00000478-200310000-00005

[9] Cenacchi, G., Giovenali, P., Castrioto, C. and Giangaspero, F. (2001) Pituicytoma: Ultrastructural Evidence of a Possible Origin from Folliculo-Stellate Cells of the Adenohypophysis. Ultrastructural Pathology, 25, 309-312. http://dx.doi.org/10.1080/019131201753136331 
[10] Vrontakis, M.E., Sano, T., Kovacs, K. and Friesen, H.G. (1990) Presence of Galanin-Like Immunoreactivity in Nontumorouscorticotrophs and Corticotroph Adenomas of the $\mathrm{Hu}-$ man Pituitary. The Journal of Clinical Endocrinology \& Metabolism, 70, 747-751. http://dx.doi.org/10.1210/jcem-70-3-747

[11] Kuebber, S., Ropte, S. and Hori, A. (1990) Proliferation of Adenohypophyseal Cells into Posterior Lobe. Their Normal Anatomical Condition and Possible Neoplastic Potentiality. Acta Neurochirurgica (Wien), 104, 21-26. http://dx.doi.org/10.1007/BF01842888

[12] Sano, T., Kovacs, K.T., Scheithauer, B.W. and Jr. Young, W.F. (1993) Aging and the Human Pituitary Gland. Mayo Clinic Proceedings, 68, 971-977.

http://dx.doi.org/10.1016/S0025-6196(12)62269-1

Submit or recommend next manuscript to SCIRP and we will provide best service for you:

Accepting pre-submission inquiries through Email, Facebook, LinkedIn, Twitter, etc. A wide selection of journals (inclusive of 9 subjects, more than 200 journals)

Providing 24-hour high-quality service

User-friendly online submission system

Fair and swift peer-review system

Efficient typesetting and proofreading procedure

Display of the result of downloads and visits, as well as the number of cited articles

Maximum dissemination of your research work

Submit your manuscript at: http://papersubmission.scirp.org/

Or contact ojmn@scirp.org 